\title{
CrimRxiv
}

\section{Data-Informed Crime Prevention at Convenience Stores in Atlantic City}

Leslie W. Kennedy ${ }^{1}$, Joel M. Caplan ${ }^{1}$, Grant Drawve ${ }^{2}$

${ }^{1}$ Rutgers University - Newark, ${ }^{2}$ University of Arkansas

Published on: Apr 15, 2021

DOI: $10.21428 / \mathrm{cb} 6 \mathrm{ab} 371.5 \mathrm{c0} 04 \mathrm{fb} 8 \mathrm{c}$

License: Creative Commons Attribution-NonCommercial-NoDerivatives 4.0 International License (CC-BY-NC-ND 4.0). 


\begin{abstract}
The Atlantic City Police Department intervened to reduce robberies with an evidencebased approach. Informed by risk terrain modeling and hot spot analysis, police commanders implemented a place-based intervention focused around convenience stores. Target areas throughout the city were reprioritized each month to create a dynamic deployment strategy that efficiently allocated resources to the most vulnerable places. Risk reduction actions, such as business checks, were favored over law enforcement against people. Robberies significantly decreased by over 37\% within four months. There was a significant spatial diffusion of benefits and there were fewer arrests, as should be expected with fewer crimes and a tactical place-based, not person-oriented, approach. Implications for policy and practice are discussed within the contexts of rapid evidence-based police responses to urgent crime problems, police culture, and data analytics.
\end{abstract}

\title{
Introduction
}

Sustainable crime suppression and prevention efforts require a deep understanding of the physical environments in which offenders operate. Research indicates that certain businesses and establishments generate and/or attract crime based on their function within the environmental backcloth (Brantingham \& Brantingham, 1995). These insights allow for crime prevention strategies to be developed and to be successfully implemented (e.g., see Bichler, Schmerler, and Enriquez, 2012). Furthermore, by turning the attention to where crime is likely to occur, rather than who is likely to commit crime, there is the potential to disrupt situational contexts (Porter, Curtis, Jefferis, and Mitchell, 2019; Kennedy et al., 2018).

One commonly included crime generator/attractor is convenience stores based on their multifaceted function within communities. They offer residents basic commodities that are difficult to find without a long trek to shopping centers or grocery stores outside the neighborhood. Locations of these stores are often optimized to serve a catchment area that can be reached on foot, and sometimes they are paired with other businesses such as fast-food restaurants or pharmacies. Convenience stores become local hubs for commerce as well as gathering points for community interactions. Much has been written about prevention strategies that work to make these types of stores safer (Alizio and York, 2007; Exum, Kuhns, Koch and Johnson, 2010; White and Katz, 2013; Erickson and Stenseth, 1996; Gotham and Kennedy, 2019; Hendricks, Landsittel, Amandus, Malcan, and Bell, 1999; Hunter and Jeffrey 1992, 1997; Hunter, 1990, 1999; 
Petrosino, Fellow and Brensilber, 1992; Roesch and Winterdyk, 1986). The success of these strategies varies by location and by the commitment of the store owners to adopt them in their efforts to curtail local crime, leading way to the focus of the current study. Specifically, we present the results of a place-based intervention that extends previous research on targeting problem locations by addressing the occurrence of crime in areas surrounding convenience stores. The intervention was specifically designed to reduce robberies in Atlantic City, New Jersey. Informed by a spatial analysis of robbery incident data, the policing strategy sought to prevent crime by managing situational risks. In presenting the results of this initiative, we begin by reviewing relevant research literature on place-based interventions and work that has been done looking at crime and convenience stores. Then we discuss the methods used by the Atlantic City Police Department (ACPD) for their problem analysis and intervention strategy development and implementation followed by our findings and closing discussion.

\section{Literature Review}

\section{Place-Based Crime Prevention}

Routine activities theory reminds us that patterns of criminal victimization vary dramatically depending on the circumstances and places in which people locate themselves and their property (Cohen and Felson, 1979; Kennedy and Forde, 1990). Environmental characteristics of those places vary considerably (Brantingham \& Brantingham, 1995; Johnson, Bowers, Birks and Pease, 2008). With that, new or chronic crime problems are likely a function of the attractive or generative qualities of environments that serve as cues to motivated offenders that certain places are suitable to commit crimes (Brantingham and Brantingham, 2008; Clarke and Eck, 2005; Caplan and Kennedy, 2016). That is, if crimes cluster to form hot spots, it is probable that spatial attributes tie or anchor crime to that specific place. Spatial analytics can offer clues about where and why crimes cluster and how to change situations at places to make them less conducive to crime (Goldstein, 2018; Smit, van der Vecht, and Lebesque, 2014; Hohl, Kondo, Kajeepeta, MacDonald, Theall, et al, 2019; Kennedy, Caplan and Piza, 2018).

In Braga et al.'s (2019) meta-analysis of 65 studies, they found hot spot policing to be a robust approach for significantly reducing crime without immediate spatial displacement (Braga, Turchan, Papachristos, and Hureau, 2019). Deterrence strategies at hot spots have the effect of reducing crime in these locations (Braga, Papachristos and Hureau, 2010; Weisburd, 2008; Hart \& Zandbergen, 2013; Chainey, Tompson, 
Uhlig, 2008; Fradella and White, 2017; Braga, Weisburd and Turchan, 2018; Kennedy, 1997, 2006). But they are sometimes short-lived (Sorg, Haberman, Ratcliffe and Groff, 2013; Sherman, 1990; Ratcliffe, Taniguchi, Groff and Wood, 2011) because the environmental backcloth and situational contexts of crime remain unaddressed and festering. As one police chief explained, "We've had certain neighborhoods in town that have been hot spots since I was on patrol. We made a ton of arrests. But, you know what? They were still hot spots..." (Melamed, 2017). In short, attempting to arrest their way out of a problem did not solve the underlying opportunity structure of crime occurrence.

Focusing on environmental features of spaces that correlate with crime hot spots can further focus strategies for interventions at these places. The notion that crimes emerge and spatially concentrate where there is something about the place that attracts illegal behaviors and leads to crime outcomes is grounded in theory (Kennedy, Caplan, Piza, \& Buccine-Schraeder, 2016; Brantingham \& Brantingham, 1981; Quetelet, 1984; Park, McKenzie \& Burgess, 1925; Shaw \& McKay, 1969; Brantingham \& Brantingham, 1995) and is well supported by research literature (Sherman, 1995; Sherman, Gartin, and Buerger, 1989; Ratcliffe \& McCullagh, 1998; Ratcliffe \& Rengert, 2008; Johnson et al., 2008; Caplan \& Kennedy, 2016; Garnier, Caplan, and Kennedy, 2018; Connealy \& Piza, 2019). Places can be "fantastically dynamic" (Jacobs, 1961/1992; p. 14) and the social relevancy (Kinney, 2010) of environmental features can affect their spatial influences at different times and under particular circumstances (Irvin-Erickson, 2015). Environmental criminology considers interactions among people, their geographies and crime. These are deeply fluid and something that must be considered carefully through data analyses to inform decisions about how to change environmental and situational factors to disrupt spatial risks and prevent crime outcomes (Kennedy et al., 2018).

Building consensus around situational contexts that lead to crime problems can be difficult because there can be multiple explanations of what the "truth" is (Moezzia, Mithra, Jandab, and Rotmann, 2017). People may be convinced of reasons for things happening based on their past experiences, what other people tell them, or their assumptions about how things work. Countering these assumptions with facts via data analytics is needed. Creating hypotheses about the situational contexts for crime at problem places, or risk narratives (Kennedy et al., 2018), is also an essential component of engaging police and their community partners in the process of decisionmaking for intervention activities. Data-informed narrative building ties underlying 
circumstance to crime outcomes and permits the development of curative approaches to deal with these connections at the most vulnerable places.

\section{Convenience Stores}

Bringing the insights of environmental criminology and place-based crime interventions to the study of convenience stores provides a way of making sense out of the level of security that is needed to protect these facilities, but also understanding the role that these play in creating higher risks for crime nearby. As we suggested earlier, these establishments function as both attractors and generators of crime (Brantingham and Brantingham, 1995; Alazio and York, 2007; D'Allessio and Stohlzenberg, 1990), and have garnered specific place-based research studies (e.g., Askey, Taylor, Groff, and Fingerhut, 2018; Furr-Holden, Milam, Nesoff, Johnson, Fakunle, Jennings, and Thorpe, 2016; White and Katz, 2013).

As attractors, they offer targets for predatory crime, such as robbery or theft; and on the other hand, as generators, they could operate as venues that support or concentrate illegal activities, attracting disorder and unruly behavior because of their late hours and limited supervision. Convenience stores are also popular locations for accessing ATMs or lottery tickets, quick cash exchange locations. People rely on convenience stores for essentials like milk, bread, snacks, personal hygiene products, or cleaning supplies, particularly in urban settings where large grocery stores or pharmacies are not as readily available compared to suburban areas. Added to these considerations are their accessibility to inner city residents without cars and their late night hours of operation (Alizio and York, 2007). Based on the transient population often associated with convenience stores, their locations could act as a venue to conduct criminal activities, for drug sales, fencing of stolen goods, or other illicit behavior.

As an example, Kennedy et al. (2018) describe a risk narrative for violent crime in Jersey City, NJ that was articulated by a community stakeholder after being told that bodegas (convenience stores), vacant buildings and gas stations were diagnosed as environmental risk factors for violent crime: Many youth hang out after school near bodegas where they can easily congregate and get food, drinks and items to smoke at nearby vacant buildings. However, while bodegas close at 10 p.m., as required by city ordinance, gas stations with food marts are exempted. These 24-hour a day/7-day a week gas stations provide alternative spaces with supplies for youth to congregate late at night, creating a unique context for turf conflict, offending or victimization. This 


\section{demonstrates how convenience stores that are not necessarily direct targets of crime can influence the situational contexts of people at nearby places and foster more suitable settings for crime relative to other parts of the city.}

The types of activities that occur near convenience stores could be governed by their placement along roadways, near bus stops, or near highway on/off ramps as a product of the larger city development and zoning regulations. Furthermore, convenience stores may be adjoined to gas stations, themselves locations that are often the targets of crime, including robbery (Duffala, 1976, Faulkner, Landsittel and Hendricks, 2001; D'Allesio and Stolzenberg, 1990). That is, convenience stores themselves pose risk, but when also situated in contexts with other known crime generators and attractors, there is an increase in crime risk. Their interaction with other features of the landscape can aggravate or mitigate place-based risks of crime at the micro level as seen in crime analysis research across cities (Barnum, Caplan, Kennedy, and Piza, 2017; Connealy and Piza, 2019; Connealy, 2019). Their impact on crime may be inadvertent, as they attract deviant behavior arising from the vast quantities of people who routinely visit these facilities or pass by. Or their impact may be directly related to the services they offer and products they supply, such as automated cell phone recycling kiosks, money transfers, alcohol, or tobacco products.

In sum, research generally shows that, throughout multiple jurisdictions in many countries, convenience stores categorically connect with crime. But, oftentimes, a minority of convenience stores within a particular jurisdiction is chronically subject to crimes among the many store options throughout the landscape (see 80-20 rule discussion by Eck, Clarke, and Guerette, 2007). It is this nexus of people, places, attractors and generators of illegal behavior that warrant policing and prevention (Moezzi, et al., 2017). By interjecting spatial diagnostics into the process, police can create intervention strategies that reflect geographic relationships to be countered through situational crime prevention, and that are in line with public values and collective expectations for responses to conditions that lead to crime. It is in the latter, Taylor (2001) says, where the need for innovations lay.

Research affirms the importance of agency to address environmental factors that contribute to high-crime areas (Konda, Keene, Hohl, MacDonald, and Branas, 2015; Piza, Kennedy and Caplan, 2018; Sampson and Groves, 1989; Sampson, Raudenbush and Earls, 1997). In one intervention, the Newark, NJ Police Department developed a task force of officers who visited stores and signed-in after greeting managers to discuss any problems they were having. With the introduction of this program, the 
levels of armed violence in Newark attributable to activity around stores dropped considerably (Kennedy et al., 2018). The use of signature sheets for crime prevention is not a new innovation, as it is a tried and true staple for community police officers to use in their outreach to businesses. In this example, its impact is tested and it was used as a tool for assessing how targeted, evidence based assessments were made in particular environments that were more likely to experience problems.

The study presented here combines elements of spatial analysis and place-based approaches to crime prevention. Physical landscapes shape opportunities for crime but the outcomes are not necessarily the same from one environment to the next (Barnum et al., 2017). Consequently, place-based strategies should be customized at local levels with meaningful data analysis. To tackle the problem of an increase in robberies, the ACPD analyzed robbery incident data, diagnosed environmental conditions that hosted this crime most often, and then intervened at the most vulnerable places using existing resources in optimal ways. The focus of intervention efforts was on the role that particular convenience stories played in driving these crime increases. It was hypothesized that crime would significantly decrease.

\section{Methods}

\section{Study area}

Atlantic City is 11 square miles of land located on an island off the coast of Southern New Jersey. The Atlantic City Police Department (ACPD) serves the local residential population of $39,558^{1}$ plus the 25 million annual visitors. $\underline{2}$ The visitor population creates a challenge for law enforcement because, while crime hot spots exist in the city, a churning population of potential offenders precludes law enforcement's primary focus on people who may commit crimes, but is ideal for a focus on places. The view of "place as case" suggests that if crime can be seen as situationally-located it is more likely to be mitigated and prevented (Lum \& Koper, 2013).

In October 2016, Atlantic City began to see a surge in robbery incidents. By January 2017 there was about a 23\% increase in robberies compared to the same four-month time period the year before. As shown by the nearest neighbor analyses presented in Table 1, robbery incidents were spatially clustered some months and randomly patterned other months; there were no obvious hot spots. Police, city officials, and other community stakeholders felt a sense of urgency to tackle this problem. $\underline{3}$

\section{Table 1 here}




\section{Intervention Planning and Deployment}

The ACPD Chief of Police, along with his command staff, initiated a crime control and prevention strategy that was data-informed, problem-oriented, and place-based. They established a practitioner-researcher partnership (McClain, 2015; Piza and Feng, 2017; Drawve, Belongie and Steinman, 2017) to analyze robbery data with Risk Terrain Modeling (RTM) and share results at the January 25, 2017 commanders meeting to be used for strategic decision-making and rapid deployment of resources to places that needed them most (i.e., priority places).

\section{Risk Terrain Modeling Analysis}

Prior to its use in Atlantic City, RTM had been tested in multiple other cities in the United States. This included a National Institute of Justice multicity study which found that policing strategies targeted at high risk places resulted in as much as $35 \%$ fewer gun crimes, $33 \%$ fewer motor vehicle thefts, and $42 \%$ fewer robberies, compared to control areas (Kennedy, et al. 2018; Nolette, 2016). Other research has demonstrated the capabilities of RTM for actionable crime analysis and resource allocation, and the strong place-based predictive validity that it can attain (e.g., Caplan, Kennedy, Piza and Barnum, 2019; Garnier, Caplan, and Kennedy, 2018; Drawve et al., 2017; Ohyama and Amemiya, 2018). RTM was used by ACPD to assess the spatial nature of robbery incidents as they related specifically to Atlantic City's environmental backcloth (Barnum et al., 2017). Grounded in crime pattern theory and environmental criminology, RTM offered police commanders information about the places where robberies were occurring so they could tailor thoughtful responses at the most criminogenic settings (Caplan \& Kennedy, 2016; Caplan, Kennedy, Barnum \& Piza, 2015). Here, RTM was performed with the RTMDx software $\underline{4}$, which has been used for similar purposes in several research studies across multiple jurisdictions $\underline{5}$.

RTMDx is a spatial diagnostic software that tests for significant relationships between attributes of the environment and crime outcomes. The first step of the RTMDx process determines if any risk factors are correlated with the robbery incident locations via an elastic net penalized regression using cross-validation. Then bidirectional stepwise regressions (Poisson and negative binomial) are performed to construct the best model from the cross-validated risk factors while minimizing the Bayesian Information Criteria (BIC) value (see Caplan, Kennedy and Piza, 2013 for full statistical steps). RTMDx analyzes multiple risk factors simultaneously to determine how the co-location of multiple factors creates risky environments for crime. Risk 
terrain maps and tables listing the significant risk factors that comprise the maps are the analytical products. For each significant risk factor, tabular outputs include a relative risk value (RRV), which is the exponentiated factor coefficient (i.e., relative weight). A relative risk score (RRS) is assigned to each micro place of the risk terrain maps to convey the full range of spatial risks of crime throughout the study area. Highest-risk places are defined as places greater than two standard deviations from the mean RRS.

Potential crime attractors and generators (i.e., environmental risk factors) were identified that could lead to disorder at places within Atlantic City's environmental backcloth based on a literature review and professional insights from ACPD officers. This selection followed the advice of Ratcliffe and McCullagh (1998) who argue that the experience of practitioners should be considered in order to unravel potentially relevant factors. Datasets for these risk factors were obtained from city administrative records and InfoGroup $\underline{6}$ and then ground-truthed by ACPD commanders for accuracy and construct and content validity before serving as inputs for RTM, as recommended by Caplan and Kennedy (2016). In addition to convenience stores, twenty-eight risk factors were available: Adult Businesses \& Restaurants, Auto Repair Shops, Bail Bonds, Banks, Beauty/Hair Shops, Check Cashing, Gas Stations, Child Care Centers, Hotels \& Rooming Houses, Laundromats, Liquor Stores, Pharmacies, Recreation (Golf, Ice Rink, Billiards, Pier), Parking Lots, Parks, Pawn \& Second-hand stores, Bars, Eat-in Restaurants, Take-out Restaurants, Retail: Clothing \& Accessory, Retail: Jewelry, Schools, Spa \& Massage Parlors, Variety Stores, Vacant Properties, Public \& Section VIII Housing, Social Services, Parolee Residences. This list of potential risk factors reflects input from both researchers and practitioners, reflecting the steps taken to increase officer buy-in to a new process. These factors have been examined in previous literature for their impact on crime outcomes and reflect a reliable cross-section of the environmental backcloth (Caplan and Kennedy, 2016).

A risk terrain model to inform the intervention strategy (that was slated to begin February 1, 2017) was produced to diagnose the most significant attractors/generators of robbery incidents that had occurred within the recent past two months (from December 2016 through January 2017; N=51). This procedure for analyzing two months of data with RTM to make next-month predictions is recommended by Caplan and Kennedy (2016) and has been demonstrated in several research studies to be valid and reliable (e.g., Caplan, Kennedy, Piza and Barnum, 2019; Ohyama and Amemiya, 2018). The average street block length in Atlantic City is 308 feet; places equal to 154 feet by 154 feet were the units of analysis. Convenience stores emerged as the top risk 
factor, with a relative risk value (RRV) of 13.06. This meant that places within one block from a convenience store were at least thirteen times more likely to experience robberies compared to other places in the city. Similar interpretations could be made for the two other significant risk factors shown in Table 2. Comparisons across risk factors can also be made using these RRVs; places around convenience stores were 2.6 times more likely to experience robberies than places around hotels and rooming houses. Risk terrain maps showed places that were affected by one or more of these risk factors, with relative risks at places throughout the city reflected by relative risk scores (RRSs). The highest-risk places identified by this risk terrain model had RRSs ranging from 34.18 to 143.17 . So, these places had a likelihood of robbery that was at least 34 times greater than elsewhere in Atlantic City. These results were presented to the ACPD commanders.

\section{Table 2 here}

The areas within 1-block from convenience stores became the 'target areas'. This involved 101 convenience stores in target areas throughout the city, which covered a total of 0.67 square miles. Upon arrival at these areas, patrol officers were instructed to conduct property checks and "meet-and-greets" with convenience store managers. Mirroring the intervention performed in Newark (Kennedy, Caplan and Piza, 2015), a business visit log was created by the ACPD in collaboration with members of the city's mercantile association to record police officer engagements with store managers. These engagement activities were supplemented with directed police patrols within the 1-block area around convenience stores at least once every shift (Koper, 1995; Sherman, 1990).

\section{Deployment Strategy}

The intervention began February 1, 2017. Police officers received maps showing the target areas within every patrol district. They also received instructions about what convenience stores to focus on at these places while on patrol, and what to do when they arrived. An obligation of targeted activities around each of the 101 convenience stores every shift could have appeared overwhelming or unmanageable given limited resources and unpredictable call-for-service volumes, so a subset of convenience stores was prioritized each month. This served three purposes: First, it helped optimize the allocation of limited patrol resources without the need for overtime or extra funding. Second, it reduced the likelihood of alert fatigue (Johnson, Birks, McLaughlin, Bowers and Pease, 2007; Caplan, Kennedy and Piza, 2013b; Skogan, 2008) among police officers who would otherwise be assigned to focus on the same 
target areas for long or uncertain periods of time. And finally, it allowed for ongoing assessments that were sensitive to the expected risk reduction impact of activities at the priority target areas each month (Zipkin, Short, Pertozzi, 2014). Basically, this tactical prioritization helped to shake things up and keep things fresh. It also grounded the deployment strategy in long-standing conclusions reached by Sherman (1990) who, following a review of eighteen case studies, asserted that police presence could be made more effective if it is limited in duration and rotated across different target areas. This is precisely what ACPD did.

To select priority target areas each month, risk terrain models and kernel density estimate (KDE) hot spot maps were produced using crime data from the two previous months. For instance, robbery patterns from January through February were analyzed to identify high-risk places for the month of March; February through March crime patterns were analyzed to identify high-risk places for the month of April; and so on. Target areas (that is, the 1-block area around convenience stores) were given priority for the month if they overlapped with high-risk places (via RTM) that also intersected current hot spots (via KDE values > two standard deviations from the mean), as depicted in Figures 1 through 4. While the intervention activities remained the same for the duration of this initiative, the deployment areas changed monthly according to the updated analyses and related prioritizations. The initiative lasted four months, from February through May, 2017. In review, the intervention strategy was a datainformed staggering of business checks at selected convenience stores and directed police patrols up to one-block around their vicinity during every 8-hour shift.

Figures 1,2,3,4 here

\section{Outcome Assessment}

The targeted place-based initiative was expected to yield significant reductions in robbery crimes throughout the entire intervention period. Data were collected every month on policing activities (what and where), to be used for the outcome evaluation. Over 1,100 business checks with sign-ins were recorded during the intervention period. On average, 67 different convenience stores were visited each month (range: 34-79), with approximately 279 total sign-ins per month, or about three per shift. February's target area convenience stores recorded 121 police officer signatures on their sign-in sheets. March recorded 529 signatures. April and May recorded 246 and 217 , respectively. While there is no estimate of the time spent at each location, the sign-in sheets record a sustained presence over time at these locations. 
At the start of the intervention in February, convenience stores were a top risk factor, with a relative risk value (RRV) of just over 13 according to the RTM analysis. By May, convenience stores had a RRV of 8.7, as shown in Figure 5, and were no longer a top risk factor compared to the other significant factors included in the models. By June, convenience stores were not significant attractors/generators of robbery and dropped from the risk terrain model altogether. Encouraged by these risk reductions, we proceeded to evaluate whether crimes significantly decreased as a result of the police intervention.

\section{Figure 5 here}

\section{Crime Drops}

We analyzed the impact of the initiative in terms of what would be expected from a crime suppression program implemented in the midst of a pressing robbery problem, that is, immediate results relative to the recent past experience with the problem athand. We identify this approach as a limitation because it is not a random assignment of control and treatment areas and the intervention was started and stopped somewhat abruptly; however, it was done on the orders of ACPD commanders and likely reflects the general reality of operational decision-making within many police departments. The pre-intervention period is October 1, 2016 through January 31, 2017 and the postintervention period is February 1, 2017 through May 31, 2017. Robbery crime data were obtained from the ACPD records management system and manually verified by ACPD staff (and interns) for reliability and validity. It was provided at the address level and then geocoded to point features in ArcGIS shapefile format.

In the pre-intervention period, the City of Atlantic City recorded 79 robberies within 1block of convenience stores. During the post-intervention period, the city recorded 29 robberies within 1-block of convenience stores. This represents a $37.9 \%$ reduction of robberies in the target areas. As shown in Table 3, a paired samples T-test suggests these results are statistically significant $(\mathrm{p}<0.001)$. One-block buffers around target areas were used to assess displacement or diffusion of benefits via a weighted displacement difference (WDD) test (Wheeler and Ratcliffe, 2018). The WDD extends from Bowers and Johnson's weighted displacement quotient. The WDD is capable of calculating the standard errors through an underlying assumption of crime counts reflecting a Poisson distribution. The WDD operates using control areas for both the treatment and displacement areas and "provides an estimate of the uncertainty in the change of crime due to an intervention" (Wheeler and Ratcliffe, 2018). The WDD is calculated from: 
$\mathrm{WDD}=\Delta T-\Delta C t+\Delta D-\Delta C d$

Where $\Delta T=$ Treatment $_{1}-$ Treatment $_{0} ; \Delta C t=$ Control treatment $_{1}-$ Control $_{\text {treatment }}$

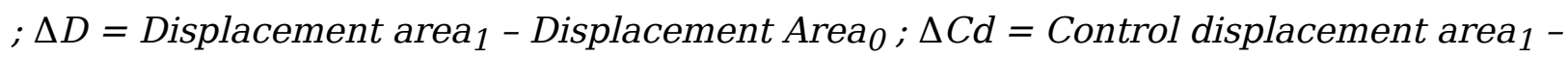
Control displacement area.$\underline{7}$

In the current study, we used the rest of the city as our control area, resulting in no direct displacement area to be considered. The WDD results indicated a significant decrease in crime in the treatment areas compared to the rest of the city (WDD $=-21$; Std. Error $=13.30 ; Z=-1.59$ ). For the treatment areas, there were 79 pre and 29 post intervention robberies. For the rest of the city, there were 49 pre and 20 post robberies. Significant crime reductions remain using the WDD Area calculation (updating based on no displacement; Treatment $=0.66 \mathrm{sqmi}$; Rest of City $=3.43 \mathrm{sqmi}$ ).$\underline{8}$

In an attempt to further test our findings, we considered t-1 as our control area to be able to account for a displacement area. That is, the same spatial parameters were used to identify treatment areas (within 308ft) and displacement areas (between 308$616 \mathrm{ft}$ ) with the change being time period. With this approach, t-1 control area had 43 pre, 44 post robberies and 29 pre, 20 post control displacement area robberies. For t, the displacement area had 22 pre and 9 post robberies. This led to a significant WDD of -55. Although we did not explicitly measure policing activities in the buffer areas, these areas could have benefitted from police patrols traveling through in order to reach (or depart from) the target area convenience stores. As discussed by Sorg et al. (2014) about their place-based Philadelphia Foot Patrol Experiment, police officers reported traveling outside of their beats. If an immediate proximal catchment area is used to measure displacement/diffusion of benefits, this area could reasonably be impacted by police presence, like that within the treatment area, but to a lesser degree. This could explain the diffusion of benefits realized in Atlantic City.

\section{Table 3 here}

The ACPD initiative significantly mitigated the city's growing robbery problem by suppressing these crimes to levels well-below what would normally be expected for the time period (Szkola, Piza and Drawve, 2019; McDowall, Loftin and Pate, 2012; Cohen, Gorr, and Durso, 2003; Andresen and Malleson, 2013; Drawve, Kennedy, Caplan and Sarkos, 2020). These results confirm a successful intervention strategy that suppressed crime quickly by dynamically deploying resources to the places most in need of them. 


\section{Discussion and Conclusion}

Atlantic City had a robbery problem that necessitated a citywide response. Given the unique nature of Atlantic City, as compared to many other US cities, Atlantic City proper is on an island off the coast of the continental US, making it a destination for millions of visitors a year. The approach ACPD took to understand robbery occurrence in Atlantic City relied on spatial analysis to identify where officers should devote their resources and what to do at these places. ACPD focused on convenience stores because these were identified as high-risk through the use of a spatial diagnostic tool, risk terrain modeling (RTM). Staggered business checks and directed patrols around these places offered optimal police presence resulting in crime deterrence effects. Robberies significantly reduced by over $37 \%$.

Police sometimes feel pressured to act quickly to suppress crime problems without expectations of longer-term crime prevention impacts. Reactions could take the form of "putting cops on dots" and encouraging officers to try to deter motivated offenders by actively suspecting, surveilling or stopping many people who enter high-crime areas. Offering a different approach, this study demonstrates that rapid crime suppression is possible with tactics focused on targeting high risk locations and not necessarily the people located there. There were, in fact, fewer arrests during the intervention period (February thru May $2017=886$ citywide arrests versus February thru May, $2016=1,024$ ).

Police in Atlantic City oriented their attention to the robbery problem and analyzed data to better understand this issue at-hand. Police commanders developed a datainformed action plan centered on officer interactions with convenience store properties and places nearby. In shuffling the priority of these target areas each month, ACPD applied theory and prior research evidence to a deployment strategy that added dynamism and practical utility to the intervention strategy. The resulting product was tolerable (to patrol officers), with only some target areas prioritized at once; optimal, with priority given to areas that were relatively high-crime and also vulnerable settings; flexible, with reassessments occurring regularly to tend to spatial patterns of robbery that might change in response to police presence; and anticipatory, with expectations of the potential for displacement at similarly situated settings in order to stay ahead of emerging problems elsewhere. It worked.

Rapid deployments of evidence-based strategies should be expected of $21^{\text {st }}$ century policing. Room for innovation (Taylor, 2001; Sherman, 1992) rests in the practitioners' operational plans to make the research actionable and, ultimately, effective. ACPD's 
methods and tactics demonstrate an 'absorptive capacity' (Bedford and Mazerolle, 2014; Cohen and Levinthal, 1990) to address the city's robbery problem in a pragmatic way. ACPD embraced existing research on data analysis methods, police activity and resource allocation and then assimilated and exploited it to meet their local crime suppression objectives. Bichler and Gaines (2005) report that police officers tend to believe crime problems are solvable by a combination of conventional prevention techniques. These involve increased police presence or educational campaigns, and novel techniques, such as forming partnerships with community stakeholders. Despite their openness to other alternatives, police revert to increased enforcement and patrol because they are the most familiar 'play card of tactics' based on history and experience (Bichler and Gaines, 2005). To overcome this tendency, Bichler and Gaines suggest a need to adopt different practices that are effective and have demonstrated positive outcomes. Willis, Mastrofski and Kockel (2010, p189) state, "police culture places high value on practical experience." This means the adoption of reliable problem-identification and strategic planning that offers new options for police activity, community partnerships and related performance measures (Sparrow, 2015) for positive reinforcement (Skogan, 2008; Willis, Mastrofski and Kochel, 2010). Procedures used to analyze data and then develop and deploy intervention strategies can be salient aspects of the overall success of crime prevention initiatives, as exemplified in Atlantic City.

Reliable and valid data analysis can trigger new ways of thinking about and reacting to crime problems. "Although police may be rich in data", explains Ridgeway (2018), "we still need to improve the extraction of information and knowledge from that data and put them to use to decrease crime...." Ferguson (2017) warns of some negative consequences of 'big data policing' that should be taken seriously. But data analytics can also empower police officers to be creative in devising interventions when the analysis supports ideas that might otherwise appear as if they came from 'left-field'. Prior research has suggested that in-depth problem-solving and innovative interventions are rare among police agencies in crisis mode or under time pressure because no one in the rank-and-file wants to standout with ideas that divest from the status quo or expected ways of doing things (Willis, Mastrofski and Kochel, 2010; Willis, Mastrofski and Weisburd, 2007; Braga and Weisburd, 2006). In contrast, ACPD's experience supports the conclusion reached by Willis, Mastrofski and Kochel (2010) that data-informed debate can help tackle the most pressing crime problems without penalizing individual officers for creative failures. If data analytics lead to a general 
consensus about how best to intervene, then either success or needs for improvement (lest not say "failure") can be mutually shared.

ACPD's focus on convenience stores prioritized through crime analysis offers new directions and opportunities for research and practice. This study adds to the state of knowledge about place-based policing and complements prior studies showing the effectiveness of crime prevention via activities directed at specific attractors and generators of criminogenic environments (Burgason, Drawve, Brown and Eassey, 2017; Brantingham et al., 2020; Ariel, Sherman and Newton, 2019; Gotham and Kennedy, 2019). It reifies findings of the Committee to Review Research on Police Policy and Practices report (Skogan \& Frydl, 2004) that geographically focused strategies have the strongest record of effect on repressing crime. It incorporates the role of personal preferences for crime, whereby the focus of place-based policing is on how individual persons select and use the environments that they occupy and the impact that this has on crime outcomes. This invites a look at behavioral outcomes more as a function of a dynamic interaction among people that occurs at places.

The demand for immediate results with limited resources is probably a familiar scenario to many police leaders. This study revealed how data analysis plays a critical role in policing under these circumstances, not only for understanding the nature of a pressing crime problem, but also for developing dynamic resource allocation protocols that are responsive to new crime patterns that emerge during the intervention (Sherman, 1990). Future research might take this even further by involving crime analysts in real-time evaluations of the propensity for new crime incidents to become instigators for near repeats within the target areas (Moreto, Piza, Caplan, 2014; Caplan, Kennedy, Piza, 2013). Piza and Feng (2017) and Drawve el al. (2017) document how crime analysts can play a pivotal role in the design of evidence-based strategies. Additionally, their involvement in spatial analysis efforts could be beneficial for inhouse outcome assessments (Piza et al., 2018).

This research may also suffer from the criticism that it is not clear what specifically led to crime reductions. Is it the fact that prospective offenders were concerned that they would be apprehended quickly because the police were arriving in an unpredictable way? Or, was it because they saw the owners and other customers forming partnerships with police that made the location less likely to tolerate crime, by reporting to police or offering resistance to attack? These questions raise the issue of the dynamics of situational crime prevention which attempts to gauge the rational choices of offenders and articulate a measured response that deters them from acting. 
The spatial approach adopted here addresses this choice in the context of place-based risk that offenders compute as part of their knowledge of an area and their view of the vulnerability of targets operating there. This approach has been explored by Garnier, Caplan and Kennedy (2018) in their assessments of how offenders navigate their environments. The disruptive nature of targeted interventions such as the one described here allows us to test the efficacy of this approach.

With the prevalence of real-time crime centers in police departments across the United States, ever-more accessible geospatial analysis technology, and professional crime analysts employed by police agencies, ACPD's initiative should be easily replicable in other jurisdictions. And it need not only be relegated to times of crisis. Future research should measure the impact of a similar strategy on different crime types and during non-crisis conditions to see if normal crime rates significantly decrease with a tactical focus on attractors and generators of the environmental backcloth prioritized at the most vulnerable places. Under these conditions, more rigorous experimental designs can be tried too.

Limitations of this study derive from the real-world nature of the intervention, structured as it was to direct police resources under pressure to address an emerging problem that created a sense of urgency among city officials and community members. The focus on convenience stores was a constant theme of the project but the stores to be targeted were not preselected and matched to controls because it was not feasible (nor tolerable) to do at the time. This may lead to a criticism that the research does not adequately compare to the gold standard of a randomized controlled trial. But the intervention program implemented by ACPD was nonetheless pragmatic and representative of the realities faced by public safety professionals to do something quickly and effectively (Bedford and Mazerolle, 2014; Willis et al., 2010). Additionally, and not unique to Atlantic City, overall crime counts for the city were not high as compared to other commonly studied locales such as Chicago, New York, Philadelphia, Los Angeles, and so on. This, coupled with the records management system of ACPD crashing in the summer of 2016 (and subsequent upgrade), limited our statistical approaches to evaluate ACPD's efforts at crime reduction along a longer timeline.

The research-practitioner partnership allowed for ACPD to implement a place-based crime reduction strategy. The researchers assisted in the analytical needs missing within ACPD while input from ACPD was solicited at multiple steps to gain officer buyin. This led to ACPD successfully implementing their strategy and reducing robbery around convenience stores in Atlantic City. The strategy was straightforward and 
replicable, demonstrating that police can succeed at improving their operational impact while working closely with community stakeholders, such as business place managers, in meeting their objectives to reduce crime.

\section{References}

Alizio, A. and York, D.(2007) Robbery from convenience stores Washington, DC: Problem Oriented Guides for Police Problem-Specific Guides Series Guide No. 49.

Andresen, M.A. and Malleson, N. (2013), "Crime seasonality and its variations across space”, Applied Geography, Vol. 43, pp. 25-35.

Ariel, B., Sherman, L. W., and Newton, M. (2019). Testing Hot-Spots Police Patrols Against No Treatment Controls: Temporal and Spatial Deterrence Effects in the London Underground Experiment. Criminology (online first).

Askey, A.P., Taylor, R., Groff, E., and Fingerhut, A. (2018). Fast Food Restaurants and Convenience Stores: Using Sales Volume to Explain Crime Patterns in Seattle. Crime \& Delinquency, 64(14): 1836 - 1857.

Barnum, J. D., Caplan, J. M., Kennedy, L. W., and Piza, E. L. (2017). The Crime Kaleidoscope: A Cross--- Jurisdictional Analysis of Place Features and Crime in Three Urban Environments. Applied Geography, 79, 203---211.

Bedford, L. and Mazerolle, L. (2014). Beyond the Evidence: Organizational Learning from RCTs in Policing. Policing, 8(4), 402-416.

Bellamy, L. (1996). "Situational Crime Prevention and Convenience Store Robbery." Security Journal 7(1):41-52.

Bowers, K.J. and Johnson, S.D. (2003). Measuring the geographical displacement and diffusion of benefit effects of crime prevention activity. Journal of Quantitative Criminology, 19: $275-301$.

Braga, A. A., \& Weisburd, D. (2010). Policing problem places: Crime hot spots and effective prevention. Oxford: Oxford University Press.

Braga, A. A., Papachristos, A. V., \& Hureau, D. M. (2012). The effects of hot spots policing on crime: An updated systematic review and meta-analysis. Justice Quarterly, 31(4), 633-663. 
Braga, A.A., Turchan, B.S., Papachristos, A.V., and Hureau, D.M. (2019). Hot spots policing and crime reduction: An update of an ongoing systematic review and metaanalysis. Journal of Experimental Criminology, 15: 289 - 311.

Braga, A. And Weisburd, D. (2006). "Problem-oriented policing: the disconnect between principles and practice." In Weisburd D. And Braga A. (eds.). Prospects and Problems in Police Innovation: Contrasting Perspectives. Cambridge: Cambridge University Press, pp. 133-152.

Braga, Anthony A., David L. Weisburd, and Brandon Turchan. 2018. "Focused Deterrence Strategies and Crime Control: An Updated Systematic Review and MetaAnalysis of the Empirical Evidence." Criminology \& Public Policy17(1):202--50.

Brantingham, P. J., Brantingham, P. L., Song, J., and Spicer, V. (2020). Crime Hot Spots, Crime Corridors and the Journey to Crime: An Expanded Theoretical Model of the Generation of Crime Concentrations. In Geographies of Behavioral Health, Crime, and Disorder. K. M. Lersch and J. Chakraborty (eds.), GeoJournal Library, 126.

Brantingham, P., \& Brantingham, P. (1981). Environmental criminology. Beverly Hills, CA: Sage Publications.

Brantingham, P., \& Brantingham, P. L. (1995). Criminality of Place: Crime Generators and Crime Attractors. European Journal on Criminal Policy and Research 3, 1-26.

Brantingham, P., and P. Brantingham. (2008). Crime pattern theory. In Environmental Criminology and Crime Analysis, eds. Richard Wortley and Lorraine Mazerolle. New York, NY: Routledge.

Burgason, K. A., Drawve, G., Brown, T. C., Eassey, J. (2017). Close Only Counts in Alcohol and Violence: Controlling Violence Near Late-Night Alcohol Establishments Using a Routine Activities Approach. Journal of Criminal Justice, 50, 62-68.

Caplan, J. M. \& Kennedy, L. W. (2016). Risk Terrain Modeling: Crime Prediction and Risk Reduction. Berkeley, CA: University of California Press.

Caplan, J. M., Kennedy, L. W., \& Piza, E. (2013a). Risk terrain modeling diagnostic user manual (version 1.0). Newark, NJ: Rutgers Center on Public Security.

Caplan, J. M., Kennedy, L. W., \& Piza, E. (2013b). Joint utility of event-dependent and environmental crime analysis techniques for violent crime forecasting. Crime and Delinquency, 59(2), 243-270 
Caplan, J. M., Kennedy, L. W., Barnum, J. D.*, \& Piza, E. L. (2015). Risk Terrain Modeling for Spatial Risk Assessment. Cityscape. 17(1), 11-20.

Caplan, J. M., Kennedy, L. W., Piza, E. L. \& Barnum, J. D.* (2019, online first). Using Vulnerability and Exposure to Improve Robbery Prediction and Target Area Selection. Applied Spatial Analysis and Policy. 1-24.

Casteel, C., and C. Peek-Asa (2000). "Effectiveness of Crime Prevention Through Environmental Design (CPTED) in Reducing Robberies.” American Journal of Preventive Medicine 18(4S):99-115.

Chainey, S., Tompson, L. \& Uhlig, S. (2008). The utility of hotspot mapping for predicting spatial patterns of crime. Security Journal, 21, 4-28.

Cheng, T. and Adepeju, M. (2014). Modifiable temporal unit problem (MTUP) and its effect on space-time cluster detection. PLoS ONE, 9(6): e100465. doi.org/10.1371/journal.pone.0100465

Clarke, R. and Eck, J. (2005). Crime Analysis for Problem Solvers in 60 Small Steps. U.S. Department of Justice Office of Community Oriented Policing Services. Washington, D.C.

Cohen, J., Gorr, W. and Durso, C. (2003), Estimation of crime seasonality: a crosssectional extension to time series classical decomposition, H. John Heinz III Working Paper No. 2003-18, Pittsburgh, PA: Carnegie Mellon University.

Cohen, L. E., \& Felson, M. (1979). Social change and crime rate trends: A routine activity approach. American Sociological Review, 44, 588-608.

Cohen, W. And Levinthal, D. (1990). Absorptive Capacity: A New Perspective of Learning and Innovation. Administrative Science Quarterly, 35(1): 128-153.

Connealy, N. T. (2019). Can We Trust Crime Predictors and Crime Categories? Expansions on the Potential Problem of Generalization. Applied Spatial Analysis and Policy, 1-24.

Connealy, N. T., and Piza, E. L. (2018). Risk Factor and High-Risk Place Variations Across Different Robbery Targets in Denver, Colorado. Journal of Criminal Justice, 60, 47-56. 
D’Allessio, S., and L. Stolzenberg (1990). "A Crime of Convenience: The Environment and Convenience Store Robbery." Environment and Behavior 22(2):255-271.

Drawve, G. \& Kennedy, L. W. Caplan, J. M., \& Sarkos, J. (2020, online first). Risk of Robbery in a Tourist Destination: A Monthly Examination of Atlantic City, New Jersey. Journal of Place Management and Development.

Drawve, G., Belongie, M., and Steinman, H. (2017). The Role of Crime Analyst and Researcher Partnerships: A Training Exercise in Green Bay, Wisconsin. Policing, 1-11.

Duffala, D.C. (1976). "Convenience Stores, Armed Robbery, and Physical Environmental Features." American Behavioral Scientist 20:227-46.

Eck, J. E., Clarke, R., \& Guerette, R. T. (2007). Risky facilities: Crime concentration in homogeneous sets of establishments and facilities. Crime Prevention Studies, 21, 225264.

Erickson, R. J., \& Stenseth, A. (1996). Crimes of convenience: A study of what motivates robbers finds that conventional wisdom may be wrong. Security Management, October, 60-63.

Exum, M. L., Kuhns, J. B., Koch, B., \& Johnson, C. (2010). An examination of situational crime prevention strategies across convenience stores and fast-food restaurants. Criminal Justice Policy Review, 21(3), 269-295.

Faulkner, K., D. Landsittel, and S. Hendricks (2001). "Robbery Characteristics and Employee Injuries in Convenience Stores." American Journal of Industrial Medicine 40(6):703-709.

Ferguson, A. G. (2017). The Rise of Big Data Policing: Surveillance, Race, and the Future of Law Enforcement. New York University Press.

Fradella, H. F. And White, M. D. (2017). Reforming Stop-and-Frisk. Criminology, Criminal Justice, Law \& Society, 18(3), pp 45-65.

Furr-Holden, C.D.M., Milan, A.J., Nesoff, E.D., Johnson, R.M., Fakunle, D.O., Jennings, J.M., and Thorpe, R.J. (2016). Not in My Back Yard: A Comparative Analysis of Crime Around Publicly Funded Drug Treatment Centers, Liquor Stores, Convenience Stores, and Corner Stores in One Mid-Atlantic City. Journal of Studies on Alcohol and Drugs, 77(1): $17-24$. 
Garnier, S., Caplan, J. M., \& Kennedy, L. W. (2018). Predicting Dynamical Crime Distribution from Environmental and Social Influences. Frontiers in Applied Mathematics and Statistics, 30.

Goldstein, H. (2018). On Problem-Oriented Policing: The Stockholm Lecture. Crime Science, 7(13) 1-9.

Gotham, K. F. and Kennedy, D. B. (2019). Analyzing Crime Foreseeability: Premises Security Litigation and the Case of Convenience Stores and Gas Stations. Security Journal, 1-24.

Hart, T. C., \& Zandbergen, P. A. (2013). Reference data and geocoding quality: Examining completeness and positional accuracy of street geocoded crime incidents. Policing: An International Journal of Police Strategies and Management, 36(2), 263-294.

Hendricks, S., D. Landsittel, H. Amandus, J. Malcan, and J. Bell (1999). “A Matched Case-Control Study of Convenience Store Robbery Risk Factors." Journal of Occupational and Environmental Medicine 41(11):995-1004.

Hohl, B. C., Kondo, M. C., Kajeepeta, S., MacDonald, J. M., Theall, P. K., Zimmerman, M. A., and Branas, C. C. (2019). Creating Safe and Healthy Neighborhoods with PlaceBased Violence Interventions. Health Affairs, 38(10), 1687-1694.

Hunter and C.R. Jeffrey (1992). "Preventing Convenience Store Robbery Through Environmental Design." In: R.V. Clarke (ed.). Situational Crime Prevention: Successful Case Studies. Albany, NY: Harrow and Heston. Jeffrey, C.R. (19

Hunter, R. (1990). “Convenience Store Robbery in Tallahassee: A Reassessment.” Journal of Security Administration 13(1, 2):3-18.

Hunter, R. (1999). “Convenience Story Robbery Revisited: A Review of Prevention Results.” Journal of Security Administration 22(1\&2):1-13.

Hunter, R., and C. Jeffery (1997). "Preventing Convenience Store Robbery Through Environmental Design.” In R. Clarke (ed.), Situational Crime Prevention: Successful Case Studies, 2nd ed. Guilderland (New York): Harrow \& Heston Publishers.

Irvin-Erickson, Y. (2014). Identifying risky places for crime: An analysis of the criminogenic spatiotemporal influences of landscape features on street robberies. (Unpublished doctoral dissertation). Rutgers University, Newark, NJ. 
Jacobs, J. (1961/1992). The death and life of great American cities. New York: Random House.

Johnson, S. D., Birks, D. J., McLaughlin, L., Bowers, K. J., \& Pease, K. (2007). Prospective crime mapping in operational context. London: Home Office.

Johnson, S. D., Bowers, K. J., Birks, D. J., \& Pease, K. (2008). Prospective mapping: The importance of the environmental backcloth. In D. Weisburd, W. Bernasco, \& G. Bruinsma (Eds.), Putting crime in its place: Units of analysis in geographic criminology (pp. 171-198). New York, NY: Springer.

Kennedy, David. 1997. "Pulling Levers: Chronic Offenders, High-Crime Settings, and a Theory of Prevention." Valparaiso University Law Review 31:449-84.

Kennedy, David. 2006. "Advocate Old Wine in New Bottles: Policing and the Lessons of Pulling Levers." In D. Weisburd and A. Braga (eds.). Police Innovation: Contrasting Perspectives. Cambridge, UK: Cambridge University Press.

Kennedy, L. W., \& Forde, D. R. (1998). When push comes to shove: A routine conflict approach to violence. Albany, NY: State University of New York Press.

Kennedy, L. W., Caplan, J. M. \& Piza, E. L. (2018). Risk-Based Policing: Evidence-Based Crime Prevention with Big Data and Spatial Analytics. Berkeley, CA: University of California Press.

Kennedy, L. W., Caplan, J. M., and Piza, E. L. (2015). A Multi-jurisdictional Test of Risk Terrain Modeling and a Place-based Evaluation of Environmental Risk-Based Patrol Deployment Strategies: Results in Brief. Newark, NJ: Rutgers Center on Public Security. Available from

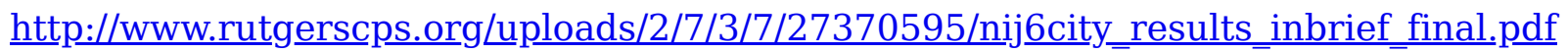

Kennedy, L. W., Caplan, J. M., Piza, E. L. \& Buccine-Schraeder, H. (2016). Vulnerability and Exposure to Crime: Applying Risk Terrain Modeling to the Study of Assault in Chicago. Applied Spatial Analysis and Policy. 9(4), 529-548.

Kinney, J. B., Brantingham, P. L., Wuschke, K., Kirk, M. G., \& Brantingham, P. J. (2008). Crime attractors, generators and detractors: Land use and urban crime opportunities. Built Environment, 34(1), 62-74.

Kondo, M., Keene, D., Hohl, B., MacDonald, J., and Branas, C. (2015). A Difference-inDifferences Study of the Effects of a New Abandoned Building Remediation Strategy 
on Safety. PLoS ONE, 10(7). DOI: 10.1371/journal.pone.0129582.

Koper, C. S. (1995) Just enough police presence: Reducing crime and disorderly behavior by optimizing patrol time in crime hot spots, Justice Quarterly, 12:4, 649-672.

Lum, C., \& Koper, C. S. (2013) Evidence-based policing in smaller agencies: Challenges, prospects, and opportunities. The Police Chief, 80, 42-47.

McClain, J. P. (2015). Atlantic County Prosecutor's Office News Release, October 13. Available from http://www.rutgerscps.org/uploads/2/7/3/7/27370595/news_release_acpd_rtm_action_i mplementation.pdf

McDowall, D., Loftin, C. and Pate, M. (2012), "Seasonal cycles in crime, and their variability”, Journal of Quantitative Criminology, Vol. 28 No. 3, pp. 389-410.

Melamed, S. (August 10, 2017). Can Atlantic City's Bold Experiment take Racial Bias out of Predictive Policing? The Philadelphia Inquirer.

Moezzia, Mithra, Kathryn B. Jandab , and Sea Rotmann 2017 Using stories, narratives, and storytelling in energy and climate change research. Energy Research and Social Science.

Moreto, W. D., Piza, E., \& Caplan, J. M. (2014). 'A plague on both your houses?': Risks, repeats and reconsiderations of urban residential burglary. Justice Quarterly. 31(6), 1102-1126.

Nolette, J. (2016). Using Research to Move Policing Forward. NIJ Journal, 276. 46-51.

Ohyama, T. and Amemiya, M. (2018). Applying Crime Prediction Techniques to Japan: A Comparison Between Risk Terrain Modeling and Other Methods. European Journal of Criminal Policy and Research, 24, 469-487. https://doi.org/10.1007/s10610-018$\underline{9378-1}$

Park, R. E., McKenzie, R. D., \& Burgess, E. (1925). The city: Suggestions for the study of human nature in the urban environment. Chicago, IL: University of Chicago Press.

Petrosino, A. J., Fellow, S., \& Brensilber, D. (1992). Convenient victims: A research note. Criminal Justice Policy Review, 8, 405-420.

Piza, E. L. and Feng, S. Q. (2017). The Current and Potential Role of Crime Analysts in Evaluations of Police Interventions: Results from a Survey of the International 
Association of Crime Analysts. Police Quarterly, 20(4), 339-366.

Piza, E. L., Kennedy, L. W., \& Caplan, J. M. (2018). Facilitators and Impediments to Designing, Implementing, and Evaluating Risk-Based Policing Strategies Using Risk Terrain Modeling: Insights from a Multi-City Evaluation in the United States. European Journal on Criminal Policy and Research, 24(4), 489-513.

Porter, L. C., Curtis, A., Jefferis, E., and Mitchell, S. (2019). Where's the Crime? Exploring Divergences Between Call Data and Perceptions of Local Crime. British Journal of Criminology, 1-24.

Quetelet, A. (1984). Research on the Propensity for Crime at Different Ages. (S.F. Sylvester, Trans.). Cincinnati, OH: Anderson Publishing. (Original work published 1831).

Ratcliffe, J. \& Rengert, G. (2008). Near repeat patterns in Philadelphia shootings. Security Journal, 21 (1-2): 58-76.

Ratcliffe, J. H., \& McCullagh, M. J. (1998). Identifying repeat victimization with GIS. British Journal of Criminology, 38(4), 651-662.

Ratcliffe, J. H., Taniguchi, T, Groff, ER \& Wood, JD (2011) The Philadelphia Foot Patrol Experiment: A randomized controlled trial of police patrol effectiveness in violent crime hotspots, Criminology, 49(3): 795-831.

Ridgeway, G. (2018). Policing in the Era of Big Data. Annual Review of Criminology, 1, 401-419.

Roesch, R., \& Winterdyk, J. (1986). The implementation of a robbery information/prevention program for convenience stores. Canadian Journal of Criminology, 28, 279-290.

Sampson, R.J., \& Groves, W.B. (1989). Community structure and crime: Testing social disorganization theory. American Journal of Sociology, 94, 774-802.

Sampson, R.J., Raudenbush, S.W., \& Earls, F. (1997). Neighborhoods and violent crime: A multilevel study of collective efficacy. Science, 277, 918-924.

Shaw, C., \& McKay, H. (1969). Juvenile delinquency and urban areas. Chicago, IL: University of Chicago Press. 
Sherman, L. (1995). Hotspots of crime and criminal careers of places. In J. E. Eck \& D. Weisburd (Eds.), Crime and Place, vol. 4 (pp. 35-52). Monsey, NY: Criminal Justice Press.

Sherman, L. W. (1990). Police Crackdowns: Initial and Residual Deterrence. Crime and Justice, 12, pp. 1-48.

Sherman, L. W. (1992). Attacking Crime: Police and Crime Control. Crime and Justice Vol. 15, Modern Policing, pp. 159-230, University of Chicago Press.

Sherman, L. W., Gartin, P. R., \& Buerger, M. E. (1989). Hot spots of predatory crime: Routine activities and the criminology of place. Criminology, 27, 27-56.

Skogan, W. \& Frydl, K. (2004). Fairness and effectiveness in policing: The evidence. Committee to review research on police policy and practices. Committee on law and justice, Divison of behavioral and social sciences and education. Washington, DC: The National Academies Press.

Skogan, W. G. (2008). Why Reforms Fail. Policing \& Society, 18(1), 23-34.

Smit, S., van der Vecht, B., and Lebesque, L. (2014). Predictive Mapping of Anti-Social Behavior. European Journal of Criminal Policy and Research, 1-13.

Sorg, E. T., Haberman, C. P., Ratcliffe, J. H., and Groff, E. R. (2013). Foot Patrol in Violent Crime Hot Spots: The Longitudinal Impact of Deterrence and Posttreatment Effects of Displacement. Criminology, 51(1), pp 65-101.

Sorg, E.T., Wood, J.D., Groff, E.R., and Ratcliffe, J.H. (2014). Boundary adherence during place-based policing evaluations: A research note. Journal of Research in Crime and Delinquency, 51(3): 377 - 393. doi.org/10.1177/0022427814523789

Sparrow, M. K. (2015). Measuring performance in a modern police organization. United States Department of Justice, National Institute of Justice.

Szkola, J., Piza, E. and Drawve, G. (2019). Risk Terrain Modeling: Seasonality and Predictive Validity. Justice Quarterly, DOI: 10.1080/07418825.2019.1630472.

Taylor, R. 2001 Breaking Away from Broken Windows N.Y.; Westview.

Wheeler, A. P. And Ratcliffe, J. H. (2018). A Simple Weighted Displacement Difference Test to Evaluate Place Based Crime Interventions. Crime Science, 7(11). Available from https://doi.org/10.1186/s40163-018-0085-5. 
White, M. D., \& Katz, C. M. (2013). Policing convenience store crime: Lessons from the Glendale, Arizona Smart Policing Initiative. Police Quarterly, 16(3), 305-322.

Willis, J. J., Mastrofski, S. D., and Kochel, T. R. (2010). Recommendations for Integrating Compstat and Community Policing. Policing, 4(2), 182-193.

Willis, J. J., Mastrofski, S. D., and Weisburd, D. (2007). "Making sense of COMPSTAT: A theory-based analysis of organizational change in three police departments." Law and Society Review. 41: 147-188.

Zipkin, Joseph \& Short, Martin \& Bertozzi, Andrea. (2014). Cops on the dots in a mathematical model of urban crime and police response. Discrete and Continuous Dynamical Systems - Series B. 19. 1479-1506. 10.3934/dcdsb.2014.19.1479.

Figure 1: Priority Target Areas for February 2017: 15 Out of 101 Convenience Stores Selected 


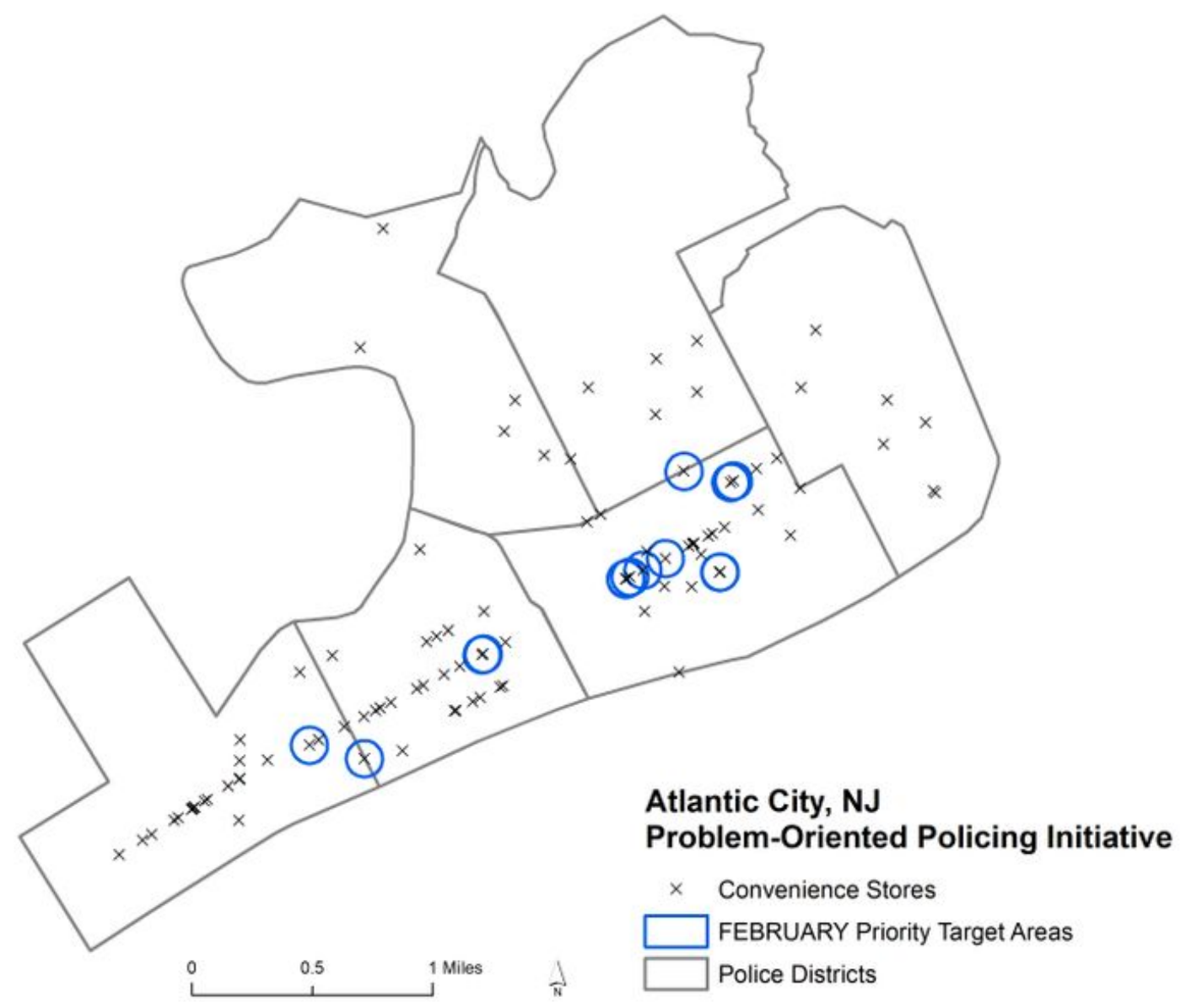

Figure 2: Priority Target Areas for March 2017: 29 Out of 101 Convenience Stores Selected 


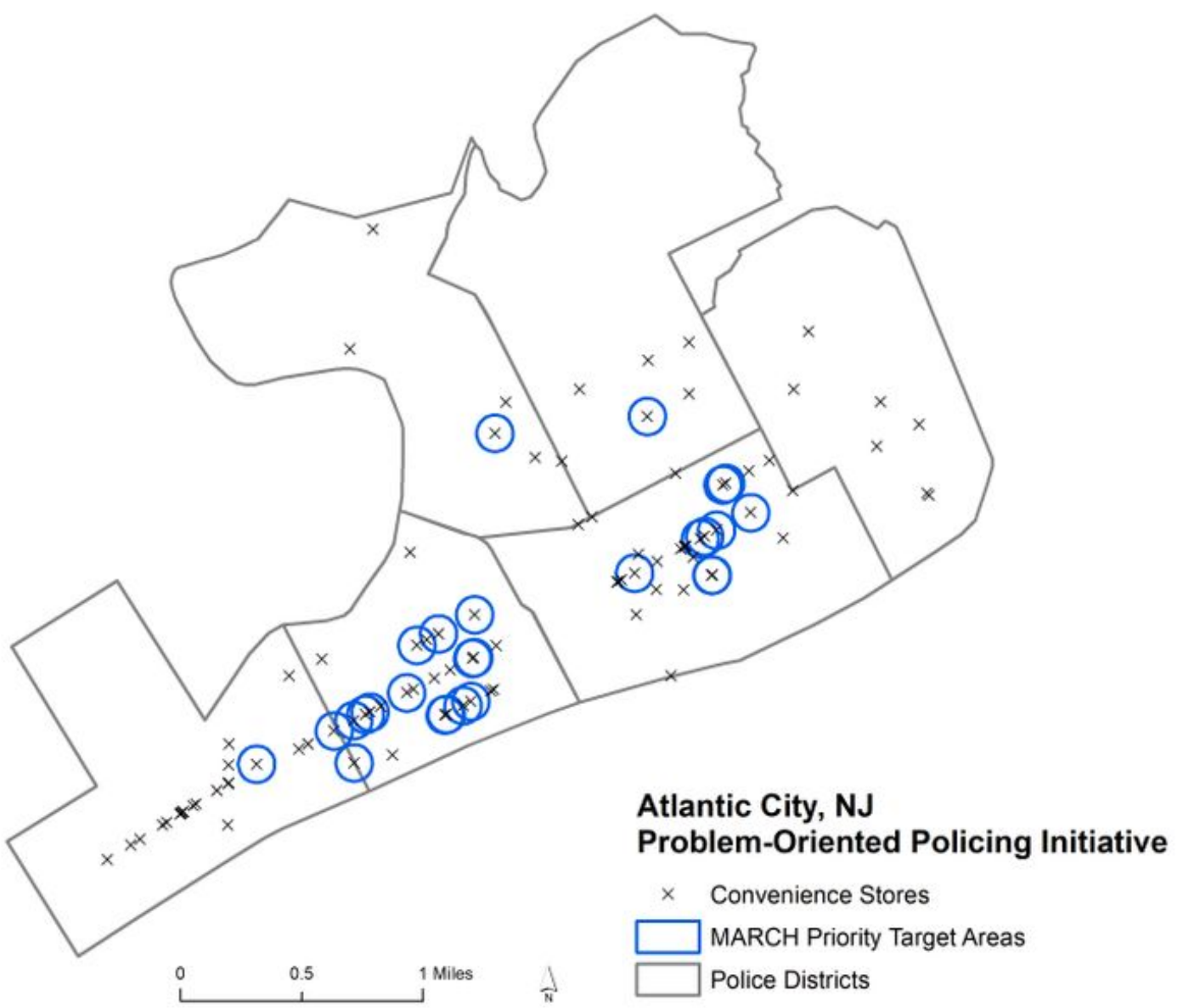

Figure 3: Priority Target Areas for April 2017: 48 Out of 101 Convenience Stores Selected 


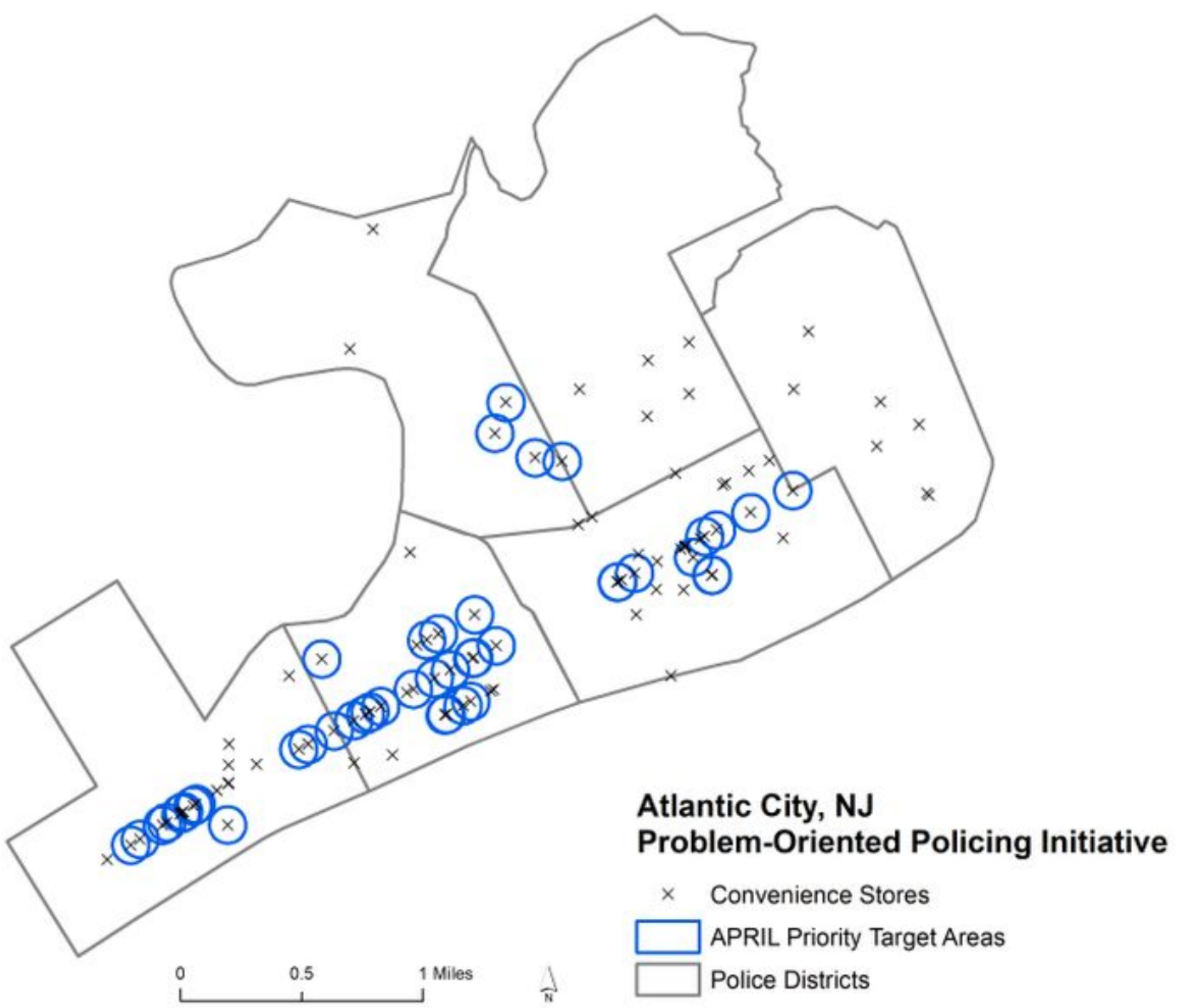

Figure 4: Priority Target Areas for May 2017: 48 Out of 101 Convenience Stores Selected 


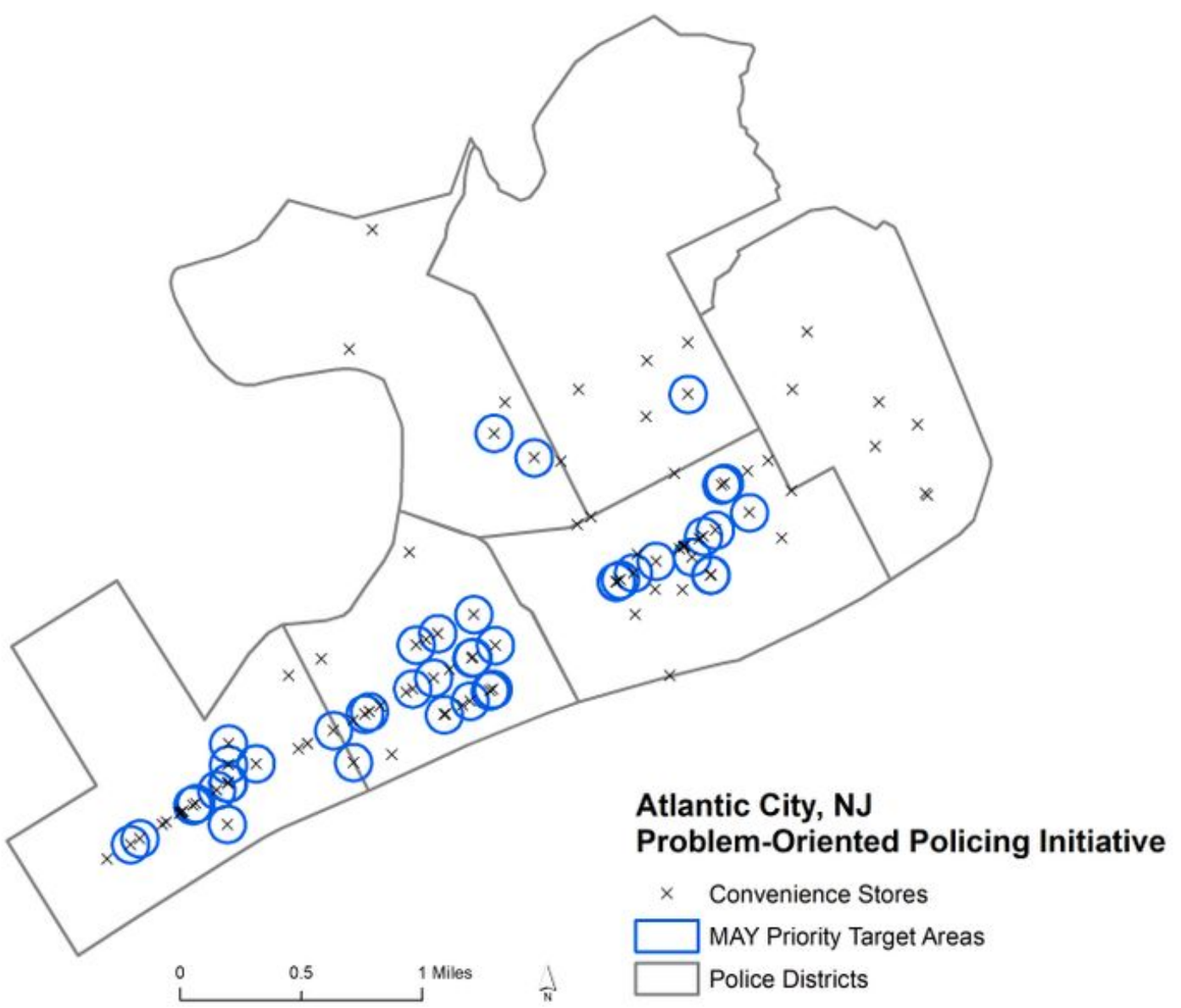

Figure 5: Relative risk values of convenience stores on robbery crimes in Atlantic City 


\section{Relative Risk Value of Convenience Stores on Robbery Crimes in Atlantic City}

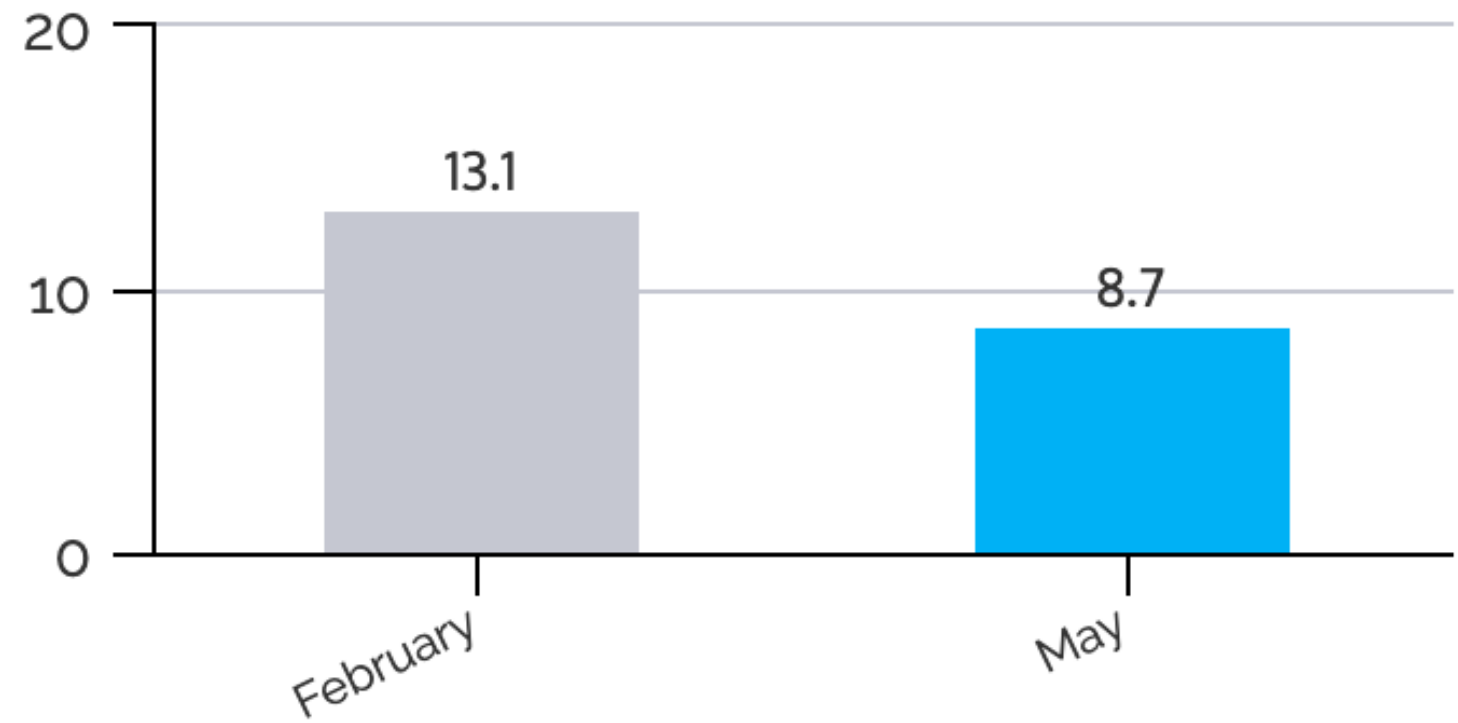

Table 1: Nearest Neighbor Analysis of Robbery Incidents by Month

\begin{tabular}{|l|l|l|l|l|l|l|}
\hline Month & $\begin{array}{l}\text { Observed } \\
\text { Mean } \\
\text { Distance }\end{array}$ & $\begin{array}{l}\text { Expected } \\
\text { Mean } \\
\text { Distance }\end{array}$ & $\begin{array}{l}\text { Nearest } \\
\text { Neighbor } \\
\text { Ratio }\end{array}$ & z-score & p-value & Spatial \\
Pattern
\end{tabular}




\begin{tabular}{|l|l|l|l|l|l|l|}
\hline $\begin{array}{l}\text { January } \\
2017\end{array}$ & 614.44 & 756.53 & 0.84 & -1.16 & 0.24 & Random \\
\hline
\end{tabular}

TABLE 2: Robbery Risk Terrain Model to Inform

POP Intervention Strategy

Significant Risk Factors (out of the 29 tested)

Convenience Stores

Hotels and Rooming Houses

Retail Jewelry Stores

Table 3: Paired Samples T-test: Robbery Counts within 1-block of convenience stores
4.96

4.89
13.06

RRV

(1)

\section{Acknowledgments}

The authors would like to thank the ACPD for their assistance and participation in this project.

\section{Footnotes}

1. U.S. Census Bureau Quick Facts (2011 estimate) http://quickfacts.census.gov/qfd/states/34/3402080.html $\leftrightarrows$ 
2. http://www.atlanticcitynj.com/!userfiles/pdfs/Reports/ACVP08 summ.pdf, http://atlanticcitymaps.com/ , http://www.visitnj.org/atlantic-city.

3. The clustering that was found in November and December could reflect changes in the larger routines of people given the holidays, or the related vacation travels to this tourist destination. The before and after 'randomness' could reflect changes in populations and their (new)routine activities at these points leading to changes in victim-offender opportunity convergence. That is, there may have been a turbulence of human activity, so to speak, that resulted in seemingly more stochastic crime patterns. Just as it is important to use small spatial units of analysis to identify geographic variation, the variation across these monthly assessments is a good reminder of how larger temporal scales could have missed the nuance (i.e., Modifiable Temporal Unit Problem - MTUP; see Cheng and Adepeju, 2014).

4. From the Rutgers University Center on Public Security: www.rutgerscps.org/software.html $\leftrightarrows$

5. For a full bibliography, see http://www.riskterrainmodeling.com/rtmworks.html $\triangleq$ 6. InfoGroup is a data and marketing services company that provides information about public entities, such as businesses/retail stores. $\_$

7. Dr. Wheeler provides further discussion of the WDD on his website. This also includes a post on the WDD when the pre/post time periods are different. See https://andrewpwheeler.com/

8. See Wheeler's blog post for the area weighted WDD: https://andrewpwheeler.com/2021/02/23/the-wdd-test-with-different-area-sizes.. 